\title{
COMMENT
}

\section{An unbiased view about bias: Not yet}

\author{
Reshma Jagsi ${ }^{1}$, Scott Rivkees ${ }^{2}$ and Valerie P. Opipari ${ }^{3}$ \\ Pediatric Research (2019) 86:10-11; https://doi.org/10.1038/s41390-019-0406-8
}

Understanding the contribution of gender bias in academic productivity, which includes publications, editorial positions, invited editorials, peer-review appointments, and more, is critical. Significant improvements in the representation of women in the medical student body and among trainees in pediatrics have not been matched with improved rates of academic advancement. In 2015, data from the Association of American Medical Colleges showed that $71 \%$ of residents and $55 \%$ of pediatric faculty were women, yet only $33 \%$ were full professors and only $19 \%$ of chairs of pediatric departments were women. ${ }^{1}$ Advancement in academics requires success in academic contributions through first and senior peer-reviewed publications, opportunities to participate in peer-review, invited editorials, and positions on editorial boards. Moreover, participation in such activities is a critical way to influence the direction of research in a field, and considerable evidence suggests that inclusion of diversity of viewpoints enriches the quality of scholarship. ${ }^{2}$

Considering these issues, we read with interest the analysis by Bearer and Molloy, investigating gender bias in article acceptance rates in Pediatric Research during the period 1 November 2017 and 9 August 2018. ${ }^{3}$ The authors found no differences in acceptance rates based on gender during this 10-month period in this unadjusted simple chi-squared bivariable analysis. Yet, while the conclusions from this report are reassuring, the period of the study is modest. It would be interesting to assess how other factors that differ by gender, such as academic rank, influenced acceptance rates. We also need to be cognizant that there are very few singleauthor reports these days and many publications include female and male authors, a challenging factor for studies of gender on acceptance rates. Thus, a first glance at gender of corresponding authors alone may not fully address the possible biases that may still exist in the peer-review process.

In reality, progress in academic representation for women has been slow. A 35-year review of the gender gap in academic medical literature revealed that the representation of women increased over time, but women have continued to constitute only a minority of authors of original research and even smaller minority of editorial board members in journals from the field of pediatrics well after women constituted a substantial proportion of medical students and majority of pediatrics residents. ${ }^{4,5}$ In addition, an analysis of women's authorship of perspective-type articles in four pediatrics journals raised concerns after finding that between 2013 and 2017, women constituted only $41.7 \%$ of the physician first authors of known gender. ${ }^{6}$

Increasing efforts of editorial boards to investigate gender bias in publication acceptance rates is important and increasingly advocated in academia. Considering the abundance of evidence regarding the role of unconscious bias in real-world decisionmaking processes, ${ }^{7}$ the possibility of bias within the system of single-blinded peer review often pursued in academic medicine might reasonably be questioned. ${ }^{8}$

Following the editorial in Science, ${ }^{9}$ identifying a low proportion of female authors as corresponding authors (16\%) and first authors (27\%), Science and the Science family of journals have embarked on a systematic effort to build a more comprehensive dataset and improved computational tools, and analyses to understand the potential contribution of gender bias in publication acceptance rates. ${ }^{10}$ This effort should provide important insight and more robust gender inference tools, and datasets to better enable more comprehensive gender-based publication analytics.

In Pediatrics, further investigation in this area is motivated by the work of Bearer and Molloy published in this edition of Pediatric Research and also based on other Editorial Board assessments in pediatric journals. In a review of more than 3700 manuscripts from 2015 to 2016 published in the Journal of Pediatrics, Williams et al. found that there were no gender differences in editor or review assignments by gender. ${ }^{11}$ Yet female editors had a lower acceptance rate overall, women were less likely to accept and complete invitations for peer review, and women wrote fewer editorialsfindings that raise new questions that require investigation.

Whereas new academic tracks are being developed at many institutions that are clinical, service and education based, academic productivity continues to be a major or minor contributing factor in promotion processes that ultimately influences who becomes eligible for leadership positions, and the influence and authority those positions allow. Thus, it is particularly important that the peer-review process is free of bias, not only to ensure the highest quality of scholarship but also to permit equity within the profession more generally. Bias may be gender-related, institution-related, academic rank-related, or related to many other overlapping characteristics or identities. In this context, it is gratifying that gender does not appear to influence recent acceptance rates in Pediatric Research.

That said, continued efforts are necessary to ensure that all promising pediatricians have the resources, including time and mentorship, necessary to contribute to scholarship in the field; after all, not all bias in academic productivity is introduced at the time of peer review alone. Concerns have been raised that promising young women who receive career development awards from the National Institutes of Health do not receive independent R01 awards at the same rate as their male peers, ${ }^{12}$ that fear may inhibit senior men from mentoring junior women, ${ }^{13}$ and that gender differences in negotiation behaviors may disadvantage women in terms of

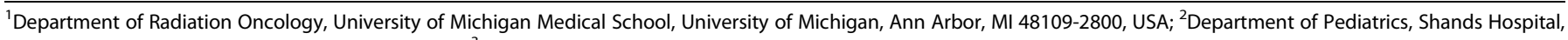

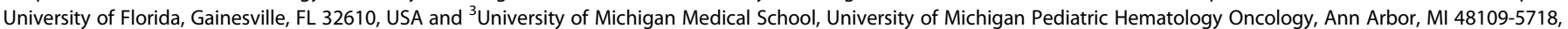
USA

Correspondence: Valerie P. Opipari (vcastle@umich.edu)

Received: 26 March 2019 Accepted: 1 April 2019

Published online: 28 May 2019 
resources and protected time for scholarship. Leaders must be cognizant of these issues and ensure that all promising pediatricians receive the support they require for success. Furthermore, women face biological constraints on the timing of their own childbearing and societal expectations of a gendered division of domestic labor that may raise additional challenges of work-life integration. ${ }^{14}$ Creative solutions to support those facing challenges from extraprofessional caregiving demands or to reward those who provide services in the workplace that otherwise go unrecognized can be important ways to support the success of all in the field, and particularly women. ${ }^{15,16}$

In summary, editorial efforts at Pediatric Research to investigate gender bias in publication rates is an important effort to ensure the integrity of the review process and to provide specific interventions to enhance fairness and ensure the very best work is published. Ongoing efforts to assess gender publication bias should continue and be guided by new analytic approaches in development and authorship submission details that better identify gender at the time of manuscript submission. Where biases are identified, procedures such as double-blinding merit consideration should be considered. Most importantly, though, we believe these findings underscore the need for efforts to ensure adequate support, including resources and time, for the many promising academic pediatricians-both men and women alikewhose perspectives are critical for the advancement of the field to generate manuscripts for consideration in the first place.

\section{ADDITIONAL INFORMATION}

Competing interests: Reshma Jagsi has stock options as compensation for her advisory board role in Equity Quotient, a company that evaluates culture in health care companies; she has received personal fees from Amgen, Vizient, and grants for unrelated work from the National Institutes of Health, the Doris Duke Foundation, the Greenwall Foundation, the Komen Foundation, and Blue Cross Blue Shield of Michigan for the Michigan Radiation Oncology Quality Consortium. The remaining authors declare no competing interests.

Publisher's note: Springer Nature remains neutral with regard to jurisdictional claims in published maps and institutional affiliations.

\section{REFERENCES}

1. The State of Women in Academic Medicine: The Pipeline and Pathways to Leadership 2013-14. Association of American Medical Colleges, 2014.

2. Page, S. E. The Difference: How the Power of Diversity Creates Better Groups, Firms, Schools and Societies. Princeton University Press, 2008.

3. Bearer, C. F. \& Molloy, E. J. Gender bias at Pediatric Research. Pediatr. Res. https:// doi.org/10.1038/s41390-018-0246-y (2018).

4. Jagsi, R. et al. The "gender gap" in authorship of academic medical literature-a 35-year perspective. N. Engl. J. Med. 355, 281-287 (2006).

5. Jagsi, R., Tarbell, N. J., Henault, L. E., Chang, Y. \& Hylek, E. M. The representation of women on the editorial boards of major medical journals: a 35-year perspective. Arch. Intern. Med. 168, 544-548 (2008).

6. Fishman, M., Williams, W. A., Goodman, D. M. \& Ross, L. F. Gender differences in the authorship of original research in Pediatric Journals, 2001-2016. J. Pediatr. 191, 244-249 (2017).

7. National Academy of Sciences, National Academy of Engineering, and Institute of Medicine. Beyond Bias and Barriers: Fulfilling the Potential of Women in Academic Science and Engineering. The National Academies Press, Washington, DC (2007). https://doi.org/10.17226/11741.

8. Jagsi, R. et al. Attitudes toward blinding of peer review and perceptions of efficacy within a small biomedical specialty. Int. J. Radiat. Oncol. Biol. Phys. 89, 940-946 (2014).

9. Berg, J. Looking inward at gender issues. Science 355, 329 (2017).

10. Berg, J. New tools for gender analysis. ScienceWebinars. http://blogs.sciencemag. org/sciencehound/2019/01/03/new-tools-for-gender-analysis/ (2019).

11. Williams, W. A., Garvey, K. L., Goodman, D. M., Lauderdale, D. S. \& Friedman Ross, L. The role of gender in publication in The Journal of Pediatrics 2015-2016: equal reviews unequal opportunities. J. Pediatr. 200, 254-260 (2018).

12. Jagsi, R., Motomura, A. R., Griffith, K. A., Rangarajan, S. \& Ubel, P. A. Sex differences in attainment of independent funding by career development awardees. Ann. Intern. Med. 151, 804-811 (2009).

13. Soklaridis, S. et al. Men's fear of mentoring in the \#MeToo Era-what's at stake for academic medicine? N. Eng. J. Med. https://doi.org/10.1056/NEJMms1805743 (2018).

14. Jolly, S. et al. Gender differences in time spent on parenting and domestic responsibilities by high-achieving young physician-researchers. Ann. Intern. Med. 160, 344-353 (2014).

15. Jagsi, R. et al. Ann innovative program to support gender equity and success in academic medicine: early experiences from the Doris Duke Charitable Foundation's fund to retain clinical scientists. Ann. Intern. Med. 169, 128-130 (2018).

16. Fassiotto, M. A. \& Maldonado, Y. A. A time banking system to support workplace flexibility. http://wellmd.stanford.edu/content/dam/sm/wellmd/documents/Timebanking-system.pdf. Accessed 19 July 2018. 